\title{
Comparing calculated, experimental and finite element analysis punch forces for the same lenght punched contours but with different geometry
}

\author{
Stelian Uțuleanu ${ }^{1,2^{*}}$, Aurelian Vlase ${ }^{1}$, Gheorghe Sindilă ${ }^{1}$, and Nicolae Căpăţână ${ }^{1}$ \\ ${ }^{1}$ Politehnica University of Bucharest, IMST Faculty, Spl. Independentei, 313, Bucharest, Romania \\ ${ }^{2}$ ICPE SA - Special Electric Machines, Splaiul Unirii 313, 030138 Bucharest, Romania
}

\begin{abstract}
When is calculated the punching force is taken into account only the length of contour and not its form. In this case, the pressing force for the contours with the same length, but with different geometries (circle, square, hexagon, triangle and shearing) may have different values. To demonstrate this hypothesis were made experimental tests which demonstrated this supposition. Also, this hypothesis was verified using the finite element analysis (FEA) in order to show the possible differences and to view the material behaviour during punching process. The calculated punching force, the experimental obtained punching force and the force determined using FEA were centralized into a table and were made graphics that show the variation of punch force according with the geometry of punched contour. The analysed materials are AISI 304, DC01, A199.8 and Brass. The software used to make the finite element analysis is Deform 3D version 6.1 (service pack 2).
\end{abstract}

\section{Introduction}

Punching is a group of cold plastic processing methods based on wholly or partially material separation, after a closed or open contour [1-2].

It is used both for obtaining finished parts and semi-finished products for further processing operations and contains several methods like: cutting, punching, shearing, notching, trimming [2-3].

The required force $\mathrm{F}$ for shearing is the force used for total separation (punching, cutting, shearing) or for partial separation (notching) of a piece of waste. This force is determined using the relation [1-3]:

$$
\mathrm{F}=\mathrm{k} \cdot 1 \cdot \mathrm{g} \cdot \tau[\mathrm{N}]
$$

where:

* Corresponding author: stelian u 86@yahoo.com 
$\mathrm{k}=1,1 \ldots 1,3$ is a coefficient that takes into account the anisotropy of mechanical properties of the material, the deviations from its thickness, the degree of wear of the cutting edges;

$l[\mathrm{~mm}]$ - punched contour length;

$\mathrm{g}[\mathrm{mm}]$ - material thickness;

$\tau\left[\mathrm{N} / \mathrm{mm}^{2}\right]$ - shear strength of the material.

After the fracture of material it is necessary to push it through the active plates. To calculate the force needed for this it is used the following relation $[1,3]$ :

$$
\mathrm{F}_{\text {push }}=\mathrm{k}_{\text {push }} \cdot \mathrm{n} \cdot \mathrm{F}[\mathrm{N}]
$$

where:

$\mathrm{k}_{\text {push }}$ is a coefficient that takes into account the type of material and its values are experimental determined ale cărui valori;

$\mathrm{n}$ is the number of pieces or waste that remain in the cutting plates from one punching to another. It is calculated with the next relation [1]:

$$
\mathrm{n}=\frac{\mathrm{h}_{\mathrm{pl}}}{\mathrm{g}}
$$

where:

$\mathrm{h}_{\mathrm{pl}}$ is the thickness of active part of cutting plates. In our case is $3 \mathrm{~mm}$.

The total punching force value is determined using the relation [1] :

$$
\mathrm{F}_{\text {tot }}=\mathrm{F}+\mathrm{F}_{\text {push }}[\mathrm{N}]
$$

The centralized values of punch forces

Table 1. Centralised values of punch forces for different materials

\begin{tabular}{|c|c|c|c|c|c|}
\hline & & AISI 304 & AISI 1008 & Al99.8 & Brass \\
\hline \hline \multirow{2}{*}{$\mathbf{k}$} & $\min$ & 1.10 & 1.10 & 1.10 & 1.10 \\
\cline { 2 - 6 } & $\max$ & 1.30 & 1.30 & 1.30 & 1.30 \\
\hline $\mathbf{L}$ & & 60.00 & 60.00 & 60.00 & 60.00 \\
\hline $\mathbf{g}$ & & 0.51 & 0.51 & 0.81 & 0.81 \\
\hline \multirow{2}{*}{$\boldsymbol{\tau}$} & $\min$ & 490.00 & 310.00 & 90.00 & 200.00 \\
\cline { 2 - 6 } & $\max$ & 520.00 & 390.00 & 150.00 & 370.00 \\
\hline \multirow{2}{*}{$\mathbf{F}$} & $\min$ & $16,493.40$ & $10,434.60$ & $4,811.40$ & $10,692.00$ \\
\cline { 2 - 6 } & $\max$ & $20,685.60$ & $15,514.20$ & $9,477.00$ & $23,376.60$ \\
\hline \multirow{2}{*}{$\mathbf{k}_{\text {push }}$} & $\min$ & 0.010 & 0.010 & 0.009 & 0.006 \\
\cline { 2 - 6 } $\mathbf{2}$ hpl & $\max$ & 0.063 & 0.063 & 0.040 & 0.031 \\
\hline $\mathbf{g}$ & & 3.00 & 3.00 & 3.00 & 3.00 \\
\hline $\mathbf{n}$ & {$[\mathrm{hpl} / \mathrm{n}]$} & 5.51 & 0.51 & 0.81 & 0.81 \\
\hline \multirow{2}{*}{$\mathbf{F}_{\text {push }}$} & $\min$ & 970.20 & 6.88 & 3.70 & 3.70 \\
\cline { 2 - 6 } & $\max$ & $7,665.84$ & $5,749.38$ & $1,40.38$ & 237.60 \\
\hline \hline \multirow{2}{*}{ Ftot } & $\min$ & $17,463.60$ & $11,048.40$ & $4,971.78$ & $10,929.60$ \\
\cline { 2 - 6 } & $\max$ & $28,351.44$ & $21,263.58$ & $10,881.00$ & $26,060.58$ \\
\hline
\end{tabular}

The analysed contour length is $60 \mathrm{~mm}$, with the gap of $0.07 \mathrm{~mm}$ between the cutting plates and the punch tools (Fig. 1 to Fig. 5). 


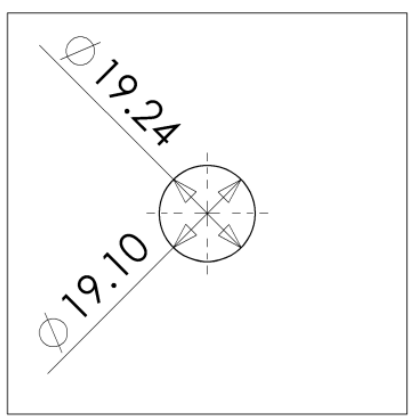

Fig. 1. Circle contour.

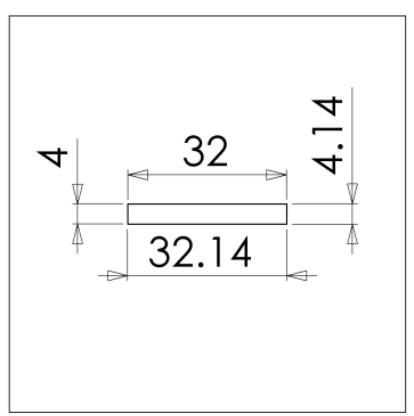

Fig. 4. Rectangular contour.

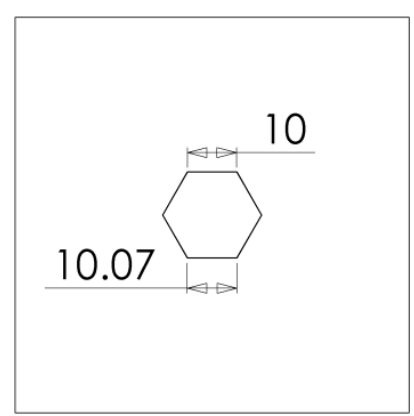

Fig. 2. Hexagon contour.

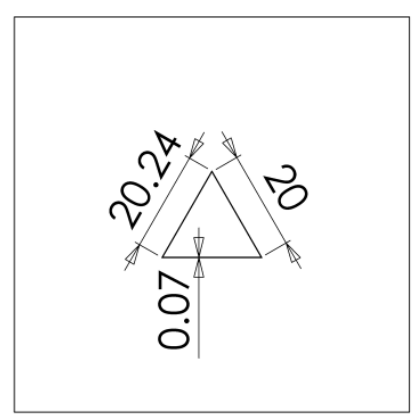

Fig. 5. Triangle contour.

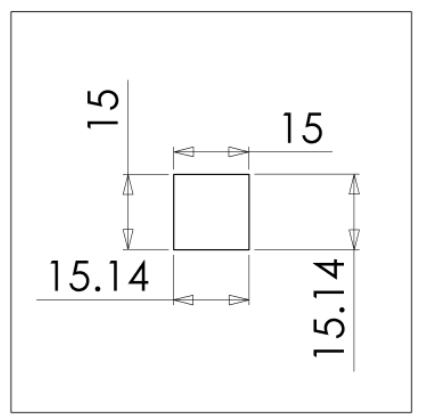

Fig. 3. Square contour.

\section{Method}

After were calculated the theoretical values of punching force they must be compared with the experimental and finite element analysis (FEA) results [4].

The software used for finite element analysis (FEA) was Deform 3D Service Pack 2. The number of mesh elements for workpiece was selected to the maximum of 100.000 elements, and the "Size ratio" as 3.

The materials used were imported from the library (AISI 304, AISI 1008, A199.8 and Brass CDA 110) and the number of steps was set to 400 and step increment to 10 .

The experimental values were obtained using a data acquisition system [5] that consists of mechanical press, force transducer, stroke transducer, one conditioner for each channel, a NI-USB-6008 data acquisition board, a server, the local area network (or Internet) and the computer from which is accessed the measuring stand.

The obtained results were centralised into a table and were made graphs to easily see the variations of punch force according with the geometry of punched contour.

In these graphs the stroke for experimental values was indexed with $9 \mathrm{~mm}$ to avoid the overlapping.

\section{Results}

The comparing results for ferrous materials are presented in the following graphs. 
AISI 304 / 1.4301 / X5CrNi18-10, 0.51 mm thickness

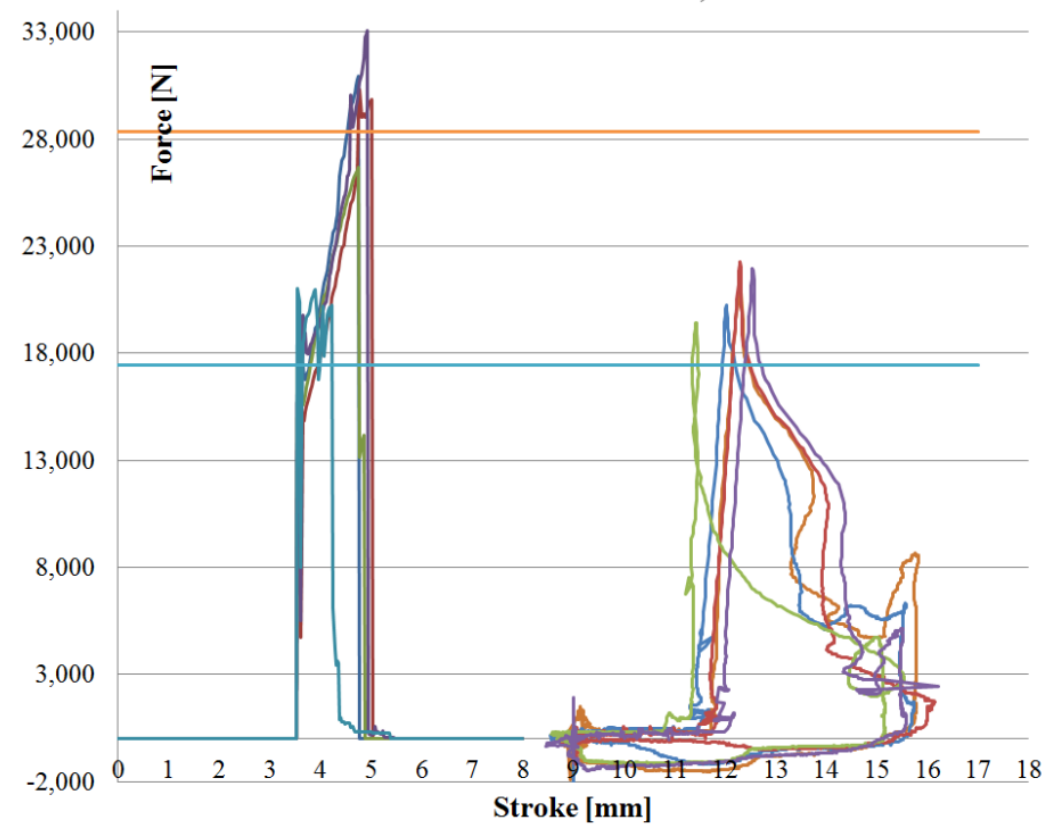

-Hexagon FEA

-Square FEA

—Cutback FEA

- Circle FEA

- Triangle FEA

- Hexagon EXP

-Square EXP

—Cutback EXP

—Circle EXP

- Triangle EXP

-Calculated min

- Calculated max

Fig. 6. Comparing results for AISI 304 material, $0.51 \mathrm{~mm}$ thickness.

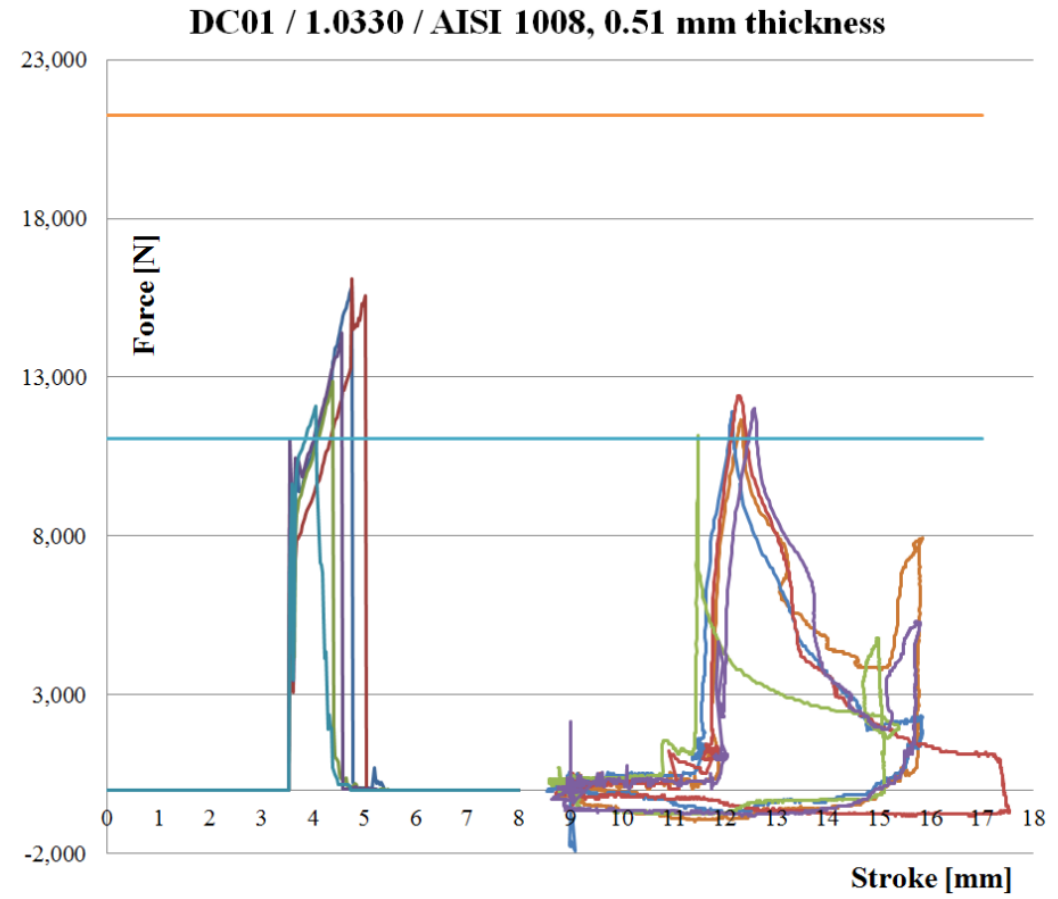

$$
\begin{aligned}
& \text { — Hexagon FEA } \\
& \text { - Square FEA } \\
& \text { - Cutback FEA } \\
& \text { —Circle FEA } \\
& \text { - Triangle FEA } \\
& \text { - Hexagon EXP } \\
& \text { - Square EXP } \\
& \text { - Cutback EXP } \\
& \text { - Circle EXP } \\
& \text { —-Triangle EXP } \\
& \text { —Calculated min } \\
& \text { —Calculated max }
\end{aligned}
$$

Fig. 7. Comparing results for AISI 1008 material, $0.51 \mathrm{~mm}$ thickness.

For non-ferrous materials the comparing results are the followings: 


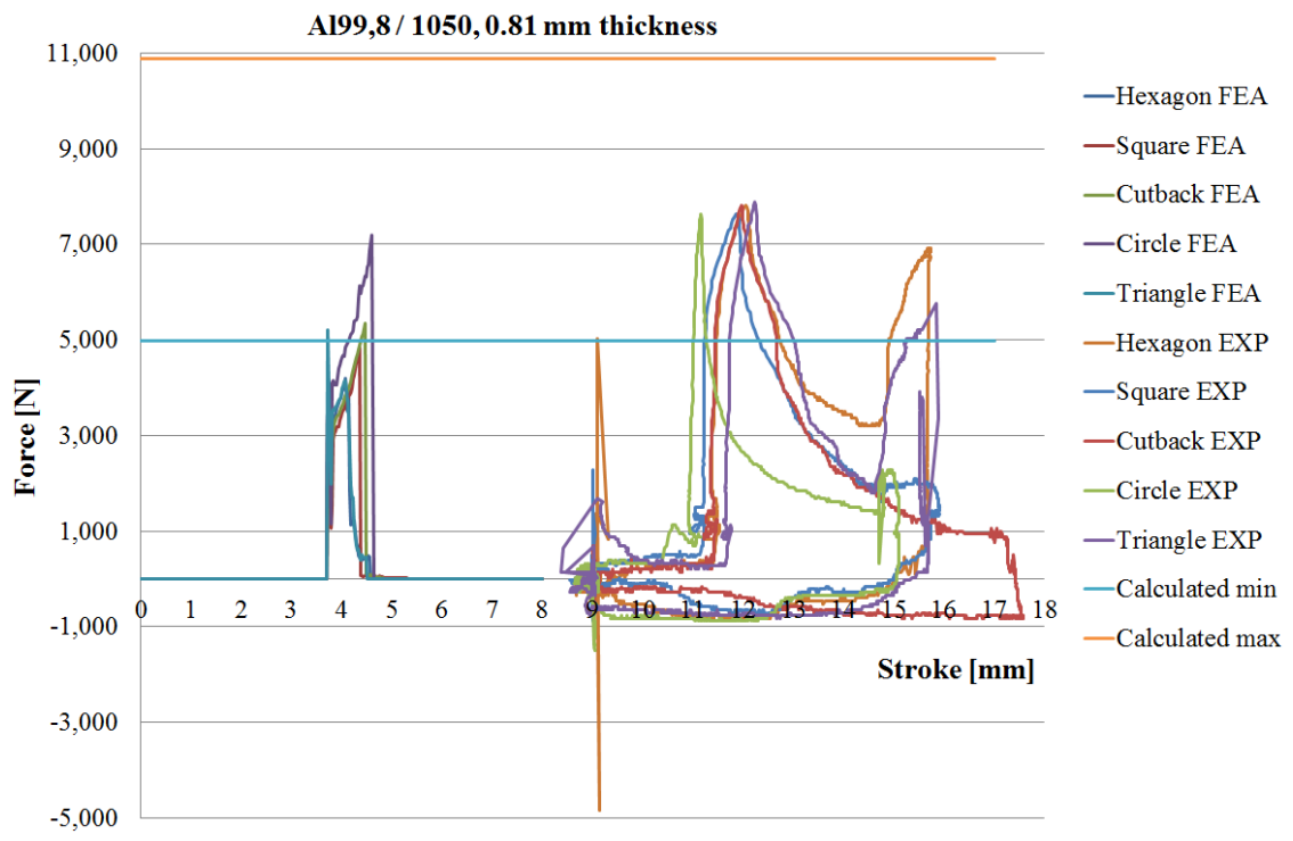

Fig. 8. Comparing results for A199.8 material, $0.81 \mathrm{~mm}$ thickness.

\section{Brass CDA110, $0.81 \mathrm{~mm}$ thickness}

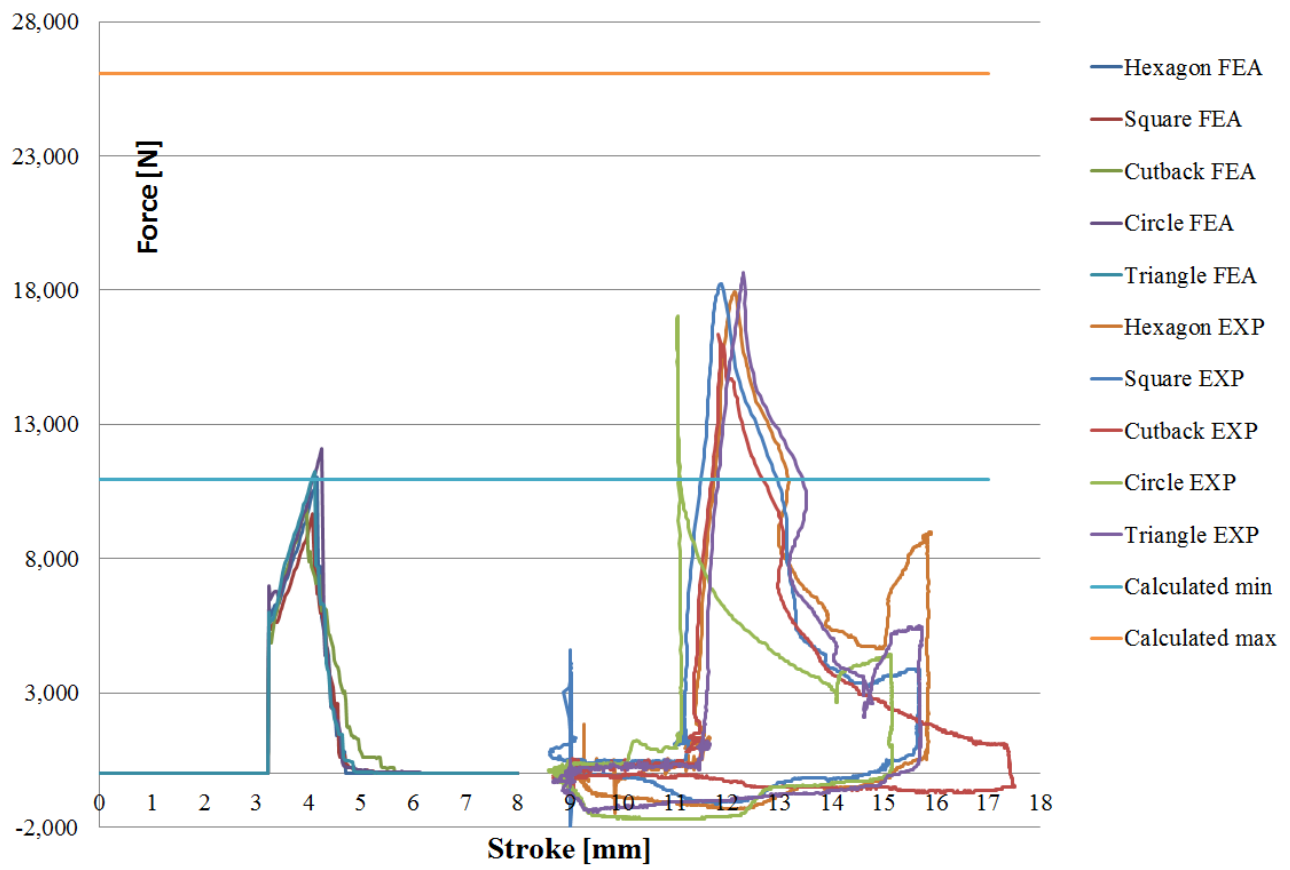

Fig. 9. Comparing results for Brass CDA 110 material, $0.81 \mathrm{~mm}$ thickness.

To easily observe the differences between the forces obtained for each type of contour geometry and materials was made a comparative table. 
Table 2. Comparison of influence of punched contour geometry over the punch force.

\begin{tabular}{|c|c|c|c|c|c|}
\hline & & AISI 304 & AISI 1008 & A199.8 & Brass \\
\hline \multirow{3}{*}{ Hexagon } & $F_{\text {con }}$ FEA & $18,366.31$ & $9,408.24$ & $3,899.60$ & $6,269.08$ \\
\hline & $F_{\max }$ FEA & $30,944.10$ & $15,870.65$ & $4,188.58$ & $11,050.73$ \\
\hline & $F_{\max }$ EXP & $21,417.20$ & $11,666.20$ & $7,826.72$ & $17,943.40$ \\
\hline \multirow{3}{*}{ Square } & $F_{\text {con }}$ FEA & $17,945.79$ & $9,938.70$ & $3,812.34$ & $5,712.40$ \\
\hline & $F_{\max }$ FEA & $30,295.54$ & $16,108.86$ & $4,836.56$ & $9,693.75$ \\
\hline & $F_{\max }$ EXP & $20,259.20$ & $11,910.00$ & $7,643.89$ & $18,248.10$ \\
\hline \multirow{3}{*}{$\begin{array}{l}\text { Shearing / } \\
\text { cutback }\end{array}$} & $\mathrm{F}_{\text {con }} \mathrm{FEA}$ & $19,980.57$ & $7,416.46$ & $2,159.76$ & $5,253.49$ \\
\hline & $F_{\max }$ FEA & $26,666.41$ & $12,880.79$ & $5,355.48$ & $9,826.86$ \\
\hline & $F_{\max }$ EXP & $22,270.40$ & $12,397.50$ & $7,826.72$ & $16,358.80$ \\
\hline \multirow{3}{*}{ Circle } & $\mathrm{F}_{\text {con }} \mathrm{FEA}$ & $17,917.21$ & $11,029.96$ & $3,951.62$ & $6,999.85$ \\
\hline & $F_{\max }$ FEA & $33,089.05$ & $14,386.40$ & $7,185.62$ & $12,095.67$ \\
\hline & $F_{\max }$ EXP & $19,406.00$ & $11,178.60$ & $7,643.89$ & $17,029.20$ \\
\hline \multirow{3}{*}{ Triangle } & $F_{\text {con }}$ FEA & $21,030.08$ & $6,854.26$ & $5,209.33$ & $6,002.73$ \\
\hline & $F_{\max }$ FEA & $21,030.08$ & $12,089.80$ & $5,209.33$ & $11,261.86$ \\
\hline & $F_{\max }$ EXP & $21,965.70$ & $12,031.80$ & $7,704.83$ & $18,674.70$ \\
\hline \multirow{2}{*}{$\begin{array}{l}\text { Calculated } \\
\text { force }\end{array}$} & $F_{\min }$ CALC & $17,463.60$ & $11,048.40$ & $4,971.78$ & $10,929.60$ \\
\hline & $\mathrm{F}_{\max }$ CALC & $28,351.44$ & $21,263.58$ & $10,881.00$ & $26,060.58$ \\
\hline
\end{tabular}

Where: "Fcon FEA" represent the force recorded when the top die hit the workpiece, "Fmax FEA" represent the maximum force recorded during FEA simulation, "F $F_{\max }$ EXP" represent the maximum values recorded during experimental test, " $F_{\min }$ CALC" and " $F$ max CALC" represent the minimum and maximum calculated forces.

As can be seen in the graphs, there is differences between FEA and experimental results and the biggest difference is that the force is decreasing after the contact between the punch tool and material in the experimental case, while in FEA simulation the force is increasing.

But in both cases the geometry of punched contour has influence over the punch force.

\section{References}

1. Gh. Sindilă, Cold plastic deformation manufacturing technologies, (Publisher Bren, Bucharest, 2007)

2. S. Uțuleanu, A. Vlase, Gh. Sindilă, N. Căpățână, ISCAME, 212, Debrecen (2013)

3. C. Ciocârdia, Cold pressing technology, Ed. Did. and Ped., R.A., Bucharest (1991)

4. S. Uțuleanu, A. Vlase, Gh. Sindilă, N. Căpățână, IManEE 2017, Iași (to be published)

5. S. Uțuleanu, A. Vlase, Gh. Sindilă, N. Căpățână, ADEM, 172, Drobeta-Turnu Severin, 2014 